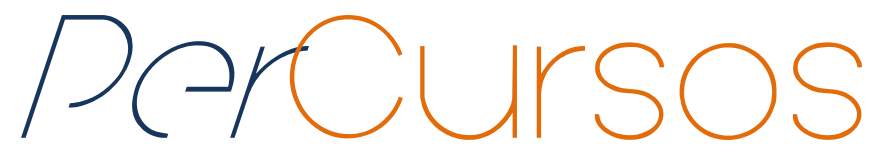

\title{
A situação atual de implementação da política nacional de proteção e defesa civil no estado de São Paulo
}

\section{Resumo}

O governo brasileiro estabeleceu, em 2012, a Lei $n^{\circ} 12.608$, que define a Política Nacional de Proteção e Defesa Civil, com objetivo de reduzir os impactos sociais e financeiros dos desastres e aprimorar atividades de coordenação entre Municípios, Estados e União. Após cinco anos, ainda não há estudos apresentando as dificuldades encontradas e a implementação efetiva da lei ainda não foi monitorada. Através de uma pesquisa exploratória realizada em 81 municípios, este trabalho avalia a situação atual dessa implementação no estado de São Paulo. Resultados mostram que, embora exista um forte movimento para o atendimento dos requisitos da lei, ainda existem muitos pontos a serem trabalhados para um pleno atendimento às exigências dessa legislação.

Palavras-chave: Lei 12.608/12. Defesa Civil. Planejamento. Resiliência. Política Nacional.

\author{
Vera Lucia Monteiro \\ Mestre em Engenharia Civil pela \\ Universidade Estadual de \\ Campinas - UNICAMP. \\ Professora da Faculdade de \\ Tecnologia de São José dos \\ Campos - FATEC. \\ Brasil \\ monteiro_vera@uol.com.br
}

\section{Irineu de Brito Junior}

Doutor em Engenharia de Produção pela Universidade de São Paulo - USP. Professor da Faculdade de Tecnologia de São José dos Campos - FATEC.

Brasil

ibritojr@yahoo.com.br

\section{Para citar este artigo:}

MONTEIRO, Vera Lucia; BRITO JUNIOR, Irineu de. A situação atual de implementação da política nacional de proteção e defesa civil no estado de São Paulo. Revista PerCursos, Florianópolis, v. 18, n.36, p. 194 213, jan./abr. 2017.

\section{DOI: $10.5965 / 1984724618362017194$}

http://dx.doi.org/10.5965/1984724618362017194 


\title{
Current situation of implementation of the national policy of civil defense and protection in the state of São Paulo
}

\begin{abstract}
The Brazilian government established in 2012 the law 12608 which defines the National Policy of Protection and Civil Defense, in order to reduce the social and financial impact of disasters and improve the coordination of activities among cities, states and union. After five years, studies have not yet presented the difficulties encountered and the effective implementation of the law has not yet been monitored. Through an exploratory survey with 81 cities, this study evaluates the current state of the implementation in the state of São Paulo. Results show that although there is a strong effort to meet the law's requirements, there are still many points to be addressed for full compliance of the requirements of such legislation.
\end{abstract}

Keywords: Brazilian Law 12608/12. Civil Defense. Planning. Resilience. National Policy. 


\section{Introdução}

Nos últimos dez anos, mais de 700 mil pessoas perderam suas vidas, mais de 1,4 milhão foram feridas e, aproximadamente, 23 milhões ficaram desabrigadas como resultado de desastres no mundo. No geral, mais de 1,5 milhão de pessoas foram afetadas por desastres de várias maneiras, sendo que a perda econômica total foi de mais de US\$ 1,3 trilhão. Os desastres vêm sendo agravados pelas alterações climáticas, que estão aumentando em frequência e intensidade, entravando, de forma significativa, o progresso rumo ao desenvolvimento sustentável (UNISDR, 2015).

Segundo dados da Organização das Nações Unidas (ONU, 2014), 70\% da população mundial viverá em centros urbanos até o ano de 2050, portanto, é de fundamental importância que se criem espaços para discussões, com o objetivo de repensar os modelos de políticas urbanas para que as cidades sejam capazes de resistir aos choques provocados pelos eventos naturais.

A busca pela redução dos impactos sociais, financeiros e, principalmente, do número de vítimas passa obrigatoriamente pela necessidade da coordenação de esforços entre municípios, estados e governo federal, pois esses são os responsáveis legais pela adequada gestão das operações de gerenciamento de desastres no Brasil. Assim, o governo brasileiro estabeleceu em 2012, através da Lei $n^{\circ} 12.608$, a Política Nacional de Proteção e Defesa Civil - PNPDEC, o Sistema Nacional de Proteção e Defesa Civil SINPDEC e o Conselho Nacional de Proteção e Defesa Civil - CONPDEC.

Neste contexto, o objetivo do estudo é avaliar a situação atual de implementação da lei, tomando por base o estado de São Paulo e, também, detectar possíveis entraves no processo de implementação dos seus requisitos, sugerindo formas de minimizar as dificuldades encontradas.

Para tanto, foi adotada a metodologia de estudo de caso, pois se trata de uma pesquisa empírica, com o objetivo de investigar um tema em seu contexto real. Também foi usada a metodologia survey, para obtenção de dados e informações sobre as 
características, ações e opiniões do grupo-alvo, mediante questionário com perguntas direcionadas.

Este artigo está assim estruturado: o primeiro tópico contextualiza e introduz o tema; o segundo define os conceitos utilizados na lei, além da própria legislação. 0 terceiro tópico descreve a metodologia utilizada; o quarto descreve os resultados encontrados. No quinto tópico é feita a análise dos resultados da pesquisa, e são feitas também algumas proposições visando auxiliar na solução dos problemas encontrados. $O$ sexto tópico finaliza o trabalho, através das conclusões do estudo.

\section{Conceitos e definições}

Neste tópico são apresentados os conceitos de desastres e de resiliência utilizados no texto e na interpretação da Lei n 12.608/2012 (BRASIL, 2012), além de uma descrição da própria legislação.

\subsection{Definições de desastre}

A Secretaria Nacional de Proteção e Defesa Civil, obedecendo a Instrução Normativa $n^{\circ} 1 / 2012$, denomina desastre como: "resultado de eventos adversos, naturais ou provocados pelo Homem, sobre um cenário vulnerável, causando grave perturbação ao funcionamento de uma comunidade ou sociedade, envolvendo extensivas perdas e danos humanos, materiais, econômicos ou ambientais, que excedem a sua capacidade de lidar com o problema usando meios próprios".

Para O'Riordan (2002), a vulnerabilidade a desastres naturais pode ser descrita como a incapacidade de uma pessoa, sociedade ou grupo populacional de evitar o perigo relacionado a catástrofes naturais, ou ao fato de serem forçados a viver em tais condições de perigo. De maneira geral, vulnerabilidade pode ser entendida como a suscetibilidade a perigo ou dano (BRAUCH, 2005). Deve-se lembrar de que a vulnerabilidade possui duas dimensões inseparáveis: a dimensão espacial e a dimensão 
social, pois trata não apenas da exposição aos riscos, mas também da capacidade de reação (ALVES e OJIMA, 2008).

De acordo com Mattedi et al. (2009) e Siebert (2012), o correto é se empregar o termo "desastre socioambiental" e não "desastre natural" por entenderem que os desastres são socialmente construídos, transformando as cidades em uma cilada, deixando todos expostos a enchentes/enxurradas, deslizamentos de terra etc.

Como pode ser notado no título do relatório do Banco Mundial de 2011: “Natural Hazards, UnNatural Disasters", se eventos geológicos, como terremotos, e hidrológicos, como chuvas fortes, são considerados ameaças naturais, os desastres não são naturais (THE WORLD BANK e UNITED NATIONS, 2010). Desastres são produzidos socialmente e a vulnerabilidade das sociedades está relacionada a seu nível de desenvolvimento econômico e social (FREITAS et al., 2012).

Quando o crescimento populacional urbano se combina aos impactos de eventos climáticos extremos e ao aumento da pobreza (um bilhão de pessoas vive hoje em favelas ou em situação de extrema pobreza) surgem novas dificuldades e mais pessoas instalamse em áreas de risco, como encostas instáveis, áreas de inundação ou costeiras. Isso acontece em decorrência de planos diretores falhos, ou pela ausência de alternativas sustentáveis, quando cidadãos não têm condições de adquirir propriedades seguras e necessitam estar próximos de suas fontes de renda. As ameaças naturais deveriam constituir uma preocupação relevante dos gestores públicos, pois os impactos desses eventos são cada vez mais onerosos para a administração pública (CAPACITAÇÃO, 2014).

\subsection{Desastres no Brasil}

Conforme os dados do EM-DAT (2014), as regiões Sul e Sudeste do Brasil foram as mais impactadas pelos desastres naturais e, nos últimos quatro anos, em todo o país cerca de 5 milhões de pessoas foram afetadas por inundações, tempestades, epidemias e secas. Convém ressaltar que, apesar de deficiências nos dados do EM-DAT que, muitas vezes, confunde inundações e deslizamentos no Brasil, estas informações são utilizadas, 
pois outros bancos de dados não proporcionam análises dos dados históricos como os ali armazenados.

A alta frequência dos deslizamentos de terra e inundações no Brasil acabou por ganhar espaço nos noticiários dos órgãos de imprensa, devido às consequências sociais e às dimensões dos prejuízos econômicos que acarretaram (MOURA; SILVA, 2008).

No Brasil, a alta densidade populacional em áreas urbanas, também acaba resultando em situações suscetíveis a inundações e deslizamentos de massa, que estão associados às chuvas de verão em várias cidades, fenômenos que se repetem e tornam-se cada vez mais intensos, devido ao aquecimento global (SANTOS, 2007).

Os desafios da administração de riscos e de desastres exigem a construção de um caminho que incorpore a gestão de riscos ao ordenamento territorial; desenvolvimento urbano; saúde; meio ambiente; mudanças climáticas; gestão de recursos hídricos; geologia; infraestrutura; educação; ciência e tecnologia; e as demais políticas setoriais, tendo em vista a promoção do desenvolvimento sustentável (CAPACITAÇÃO, 2014).

No Brasil, em termos de Legislação, a mais recente é de 10 de abril de 2012; trata-se da Lei $n^{\circ} 12.608$, que institui a Política Nacional de Proteção e Defesa Civil (PNPDEC), que dispõe sobre o Sistema Nacional de Proteção e Defesa Civil (SINPDEC) e o Conselho Nacional de Proteção e Defesa Civil (CONPDEC), transformando o sistema de Defesa Civil em um sistema de Proteção e Defesa Civil (BRASIL, 2012).

\subsection{Resiliência urbana}

Na temática dos desastres, cidade resiliente é aquela que tem a capacidade de resistir, absorver e se recuperar de forma eficiente dos efeitos de um evento adverso e, de maneira organizada, prevenir que vidas e bens sejam perdidos (UNISDR, 2010).

Resiliência urbana é um termo que está vinculado aos conceitos de desenvolvimento e crescimento urbano. Sendo assim, pode-se dizer que a resiliência é um processo e não uma nova técnica de gestão de emergências ou resposta imediata a desastres (SILVA, 2015). 
A ONU, em 2012, elaborou um guia para construção de cidades mais resilientes voltado aos gestores públicos locais. Nele, foram definidas as políticas públicas a serem desenvolvidas para que houvesse a redução dos impactos, tornando as cidades mais resilientes e habitáveis. Foram delimitadas pela ONU situações que podem impactar a resiliência das cidades e que deveriam ser observadas pelos gestores públicos locais (AMORIN;QUELHAS; MOTTA , 2014).

Segundo o UNISDR (2012), cidades resilientes possuem governos que se preocupam com uma urbanização sustentável e onde há participação da população nas decisões e no planejamento, auxiliando na redução dos desastres naturais. É onde as autoridades locais e a população compreendem os riscos que enfrentam e desenvolvem processos de informação local e compartilhada, com base nos danos por desastres, ameaças e riscos, inclusive sobre quem está exposto e quem é vulnerável. Providas de infraestrutura adequada e serviços básicos, há um controle efetivo quanto à ocupação desordenada em encostas e áreas sujeitas a inundações (CAPACITAÇÃO, 2014).

\subsection{Lei 12.608 de 10 de abril de 2012}

No Brasil, os desastres, em sua maioria, são decorrentes de má ocupação e uso indevido do solo ou de áreas que exigiriam técnicas de construção específicas, portanto, são evitáveis. Isso compete à administração pública (SANTOS, 2012) e às pessoas individualmente.

Fruto do aumento na ocorrência de desastres em diversos estados brasileiros, especialmente a ocorrência na região serrana do Rio de Janeiro em 2011, a Lei n 12.608 é um instrumento que visa auxiliar os municípios no enfrentamento de desastres. Essa lei veio ao encontro de vários anseios das Defesas Civis Estaduais, e também da sociedade como um todo. Trata-se de uma lei ambiciosa e de abordagem preventiva, e seu principal objetivo é a redução dos riscos de desastres (SANTOS, 2012).

A Lei $n^{\circ}$ 12.608/2012 também institui a obrigação das três esferas do governo, União, Estados e Municípios, de adotar as medidas necessárias para elaborar o planejamento com base em pesquisas e estudos sobre as áreas de risco, e também 
planejamentos e estudos para a preparação da cidade em ações de prevenção, mitigação, preparação, resposta e recuperação, com o objetivo de reduzir os efeitos causados pelos desastres (BRASIL, 2012).

Os municípios devem cooperar com os Estados e a União de forma a mapear as áreas de risco e adequar o Plano Diretor às disposições da Lei Federal, de maneira a considerarem, em âmbito local, as necessidades e características de cada município, que serão adotadas e elaboradas em projeto específico. Os municípios terão o prazo de cinco anos para aprovar o Plano Diretor pela Câmara Municipal (BRASIL, 2012).

Com a aprovação da nova Lei Federal, os principais objetivos são distribuir competências entre as esferas do governo e alterar o Estatuto da Cidade, determinando que todos os municípios devam mapear as áreas de risco por meio de cartas geotécnicas. Devem, ainda, realocar a população que mora nessas áreas de risco, bem como regularizar os assentamentos urbanos (SARNEY FILHO, 2012).

O governo federal priorizou a implementação da lei em 821 municípios brasileiros, dos quais 89 estão no estado de São Paulo (BELTRÃo, 2014).

O art. 8 da Lei $n^{\circ}$ 12.608, de 2012, estabelece que compete aos municípios: executar a PNPDEC em âmbito local; coordenar as ações da SINPDEC, articulando-as a outras esferas; incorporar as ações de proteção e defesa civil no planejamento municipal; identificar e mapear áreas de risco; promover a fiscalização dessas áreas; declarar situação de emergência e calamidade pública quando necessário; vistoriar edificações e áreas de risco; organizar e administrar abrigos provisórios quando for o caso; manter a população informada sobre áreas de risco e ocorrência de evento; mobilizar e capacitar os radioamadores para atuar em caso de desastre; realizar periodicamente simulações, conforme o Plano de Contingência; promover coleta de suprimentos de alívio; distribuir e controlar os suprimentos, em caso de desastres; proceder a avaliação de danos e prejuízos em áreas atingidas por desastres; estimular a participação das diversas organizações e realizar treinamento de voluntários; e prover solução de moradias temporárias para as pessoas atingidas por desastres (BRASIL, 2012). 


\section{Metodologia}

Em termos de objetivos, este trabalho é classificado como pesquisa exploratória, já que procura evidências sobre a aplicação da Lei n 12.608/12, através de questionário de pesquisa enviado aos municípios-alvos e da revisão da literatura, que proporciona um maior entendimento sobre o tema em questão.

Quanto aos procedimentos técnicos, foi utilizado o método de estudo de caso, tendo o estado de São Paulo como alvo da pesquisa. Para a coleta de dados foi utilizada a ferramenta de pesquisa via web SurveyMonkey ${ }^{\circledR}$.

Dez perguntas foram formuladas, tomando por base o Art. 8 da Lei $n^{\circ} 12.608 / 2012$, e direcionadas de forma a se obter as informações de situação de implementação no município. As perguntas foram também validadas pela Defesa Civil do estado de São Paulo.

Inicialmente, o objetivo da pesquisa era somente a avaliação dos municípios do Vale do Paraíba Paulista para detecção de necessidades de treinamento na região, todavia a pesquisa foi estendida para todo o estado por solicitação da Defesa Civil Estadual. Foram alvos do envio do questionário, os Coordenadores Municipais de Defesa Civil (COMDEC) de 324 dos 645 municípios do estado de São Paulo, e os critérios adotados para sua inclusão nesta análise foram:

1. Os 89 municípios de SP priorizados pelo Governo Federal;

2. Os 96 municípios do estado de SP, monitorados pelo CEMADEN;

3. Os 39 municípios do Vale do Paraíba Paulista; e

4. Os 243 municípios do estado de SP com número maior ou igual a 20 mil habitantes, aos quais a elaboração de um Plano Diretor é obrigatória.

A figura 1 apresenta a metodologia utilizada. 


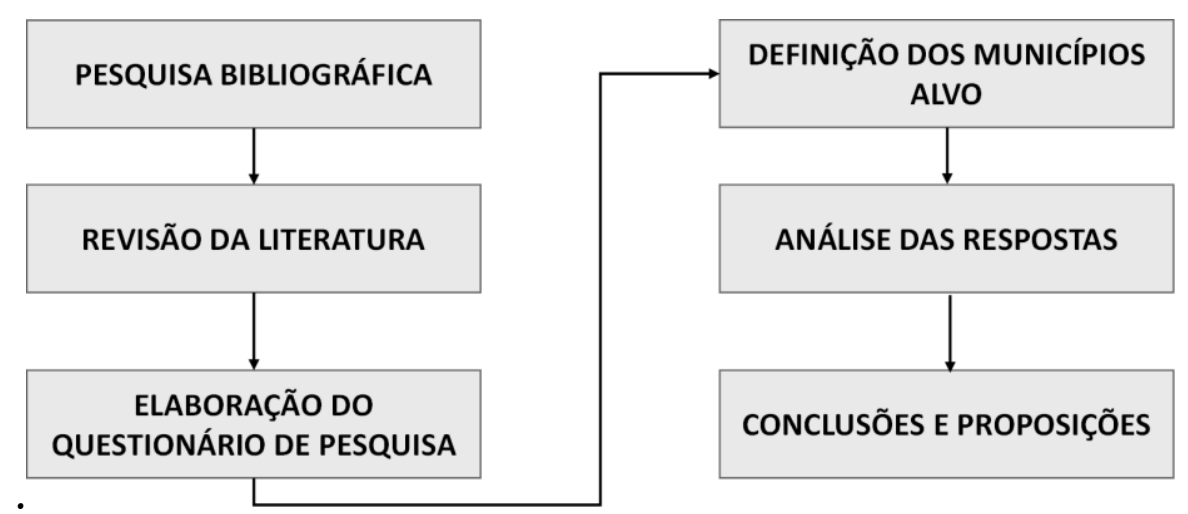

Figura 1 - Metodologia Adotada.

\section{Respostas coletadas}

O questionário, composto de dez perguntas elaboradas com o objetivo de verificar o atendimento ao artigo $8^{\circ}$ da Lei $n^{\circ} 12.608 / 12$, foi enviado aos Coordenadores Municipais da Defesa Civil de 324 municípios do estado de São Paulo, conforme explicitado na metodologia, no período entre setembro de 2015 e junho de 2016.

Um nível de confiança igual a 95\% e de erro amostral máximo admissível de 10\% foram estabelecidos como critérios de confiabilidade da amostra. De acordo com Triola (2014), seriam necessárias 75 respostas para aceitação. Foram obtidas respostas de 82 municípios, o que corresponde a pouco mais de $25 \%$ de retorno e dentro do nível de aceitação estabelecido.

As questões formuladas e as respostas obtidas em cada uma delas são apresentadas a seguir:

Questão 1: De forma geral, seu Município articula ações com a União e o Estado, com o objetivo de reduzir os desastres e apoiar comunidades atingidas?

Tabela 1 - Nível de articulação do Município com o Estado e a União.

\begin{tabular}{|l|r|}
\hline \multicolumn{1}{|c|}{ Opç̃̃es de Resposta } & $\%$ Respostas \\
\hline As articulaçoes são insipientes ou não existem & $12 \%$ \\
\hline Estamos planejando uma abordagem sistêmica & $31 \%$ \\
\hline Articulamos bem com a União e o Estado & $57 \%$ \\
\hline
\end{tabular}


Questão 2: Seu município incorpora ações de proteção e defesa civil no planejamento municipal?

Tabela 2 - Proteção e defesa civil no planejamento municipal.

\begin{tabular}{|l|r|}
\hline \multicolumn{1}{|c|}{ Opcões de Resposta } & $\%$ Respostas \\
\hline Já incorporamos ações no Planejamento Municipal & $43 \%$ \\
\hline Incorporamos em parte, ações no Planejamento Municipal & $46 \%$ \\
\hline Ainda não incorporamos ações no Planejamento Municipal & $11 \%$ \\
\hline
\end{tabular}

Questão 3: Seu município identifica e mapeia as áreas de risco de desastres?

Tabela 3 - Identificação e mapeamento de áreas de risco.

\begin{tabular}{|l|r|}
\hline \multicolumn{1}{|c|}{ Opcões de Resposta } & $\%$ Respostas \\
\hline Já temos mapeamento de risos elaborado & $80 \%$ \\
\hline O mapeamento está em andamento & $17 \%$ \\
\hline O mapeamento ainda não foi iniciado & $3 \%$ \\
\hline
\end{tabular}

Questão 4: Seu município promove a fiscalização das áreas de risco de desastre e veda novas ocupações nessas áreas?

Tabela 4 - Fiscalização da ocupação em áreas de risco.

\begin{tabular}{|l|r|}
\hline \multicolumn{1}{|c|}{ Opções de Resposta } & $\%$ Respostas \\
\hline Temos fiscalizado e vedado novas ocupações em áreas de risco & $41 \%$ \\
\hline Temos fiscalizado e vedado parcialmente novas ocupações em áreas de risco & $47 \%$ \\
\hline Ainda não fiscalizamos e vedamos as ocupações em áreas de risco & $12 \%$ \\
\hline
\end{tabular}

Questão 5: Seu município organiza e administra abrigos provisórios para assistência à população em situação de desastre, em condições adequadas de higiene e segurança?

Tabela 5 - Infraestrutura e administração de abrigos

\begin{tabular}{|l|r|}
\hline \multicolumn{1}{|c|}{ Opções de Resposta } & $\%$ Respostas \\
\hline Estamos preparados para fornecer abrigos conforme estipula a Lei & $58 \%$ \\
\hline Estamos em fase de planejamento para localização de abrigos & $28 \%$ \\
\hline Ainda não estamos preparados para o atendimento deste tópico da Lei & $14 \%$ \\
\hline
\end{tabular}

Questão 6: Seu município mantém a população informada sobre áreas de risco e ocorrência de eventos extremos (promove alertas antecipadamente)? 
Tabela 6 - Informação e alertas à população.

\begin{tabular}{|l|r|}
\hline \multicolumn{1}{|c|}{ Opções de Resposta } & $\%$ Respostas \\
\hline Já temos definido os protocolos de alerta aos moradores & $43 \%$ \\
\hline Os protocolos de alerta estão em fase final de definição & $27 \%$ \\
\hline Ainda não definimos nada sobre este tópico da Lei & $30 \%$ \\
\hline
\end{tabular}

Questão 7: Seu município realiza regularmente exercícios simulados, conforme Plano de Contingência e Defesa Civil?

Tabela 7 - Realização periódica de simulados.

\begin{tabular}{|l|r|}
\hline \multicolumn{1}{|c|}{ Opcões de Resposta } & $\%$ Respostas \\
\hline Realizamos os simulados regularmente & $30 \%$ \\
\hline Estamos organizando a implementação dos simulados & $44 \%$ \\
\hline Ainda nada foi preparado para atendimento deste tópico da Lei & $26 \%$ \\
\hline
\end{tabular}

Questão 8: Seu município tem locais previamente designados para o recebimento e a triagem de doações?

Tabela 8 - Infraestrutura para recepção e triagem de doações.

\begin{tabular}{|l|r|}
\hline \multicolumn{1}{|c|}{ Opç̃es de Resposta } & $\%$ Respostas \\
\hline Meu Município já possui locais designados para isso & $65 \%$ \\
\hline Estamos em fase de definição dos melhores locais & $17 \%$ \\
\hline Ainda não temos locais designados para isso & $18 \%$ \\
\hline
\end{tabular}

Questão 9: O pessoal que fará o recebimento e a separação das doações está treinado nos métodos adequados de triagem de material?

Tabela 9 - Treinamento em triagem de doações.

\begin{tabular}{|l|r|}
\hline \multicolumn{1}{|c|}{ Opções de Resposta } & \% Respostas \\
\hline SIM & $58 \%$ \\
\hline NÃO & $42 \%$ \\
\hline
\end{tabular}

Questão 10: No seu município, existem critérios claramente definidos para compra de itens necessários e/ou solicitados nas operações de respostas a desastres?

Tabela 10 - Critérios para compra de suprimentos.

\begin{tabular}{|l|r|}
\hline \multicolumn{1}{|c|}{ Opções de Resposta } & Respostas \\
\hline SIM & $58 \%$ \\
\hline NÃO & $42 \%$ \\
\hline
\end{tabular}




\section{Análise das respostas e proposições}

As questões 1 e 2 referem-se ao planejamento e integração de ações para redução de desastres, quer sejam no âmbito das articulações com o Estado e a União, quer sejam nas esferas do planejamento municipal. O que se percebe nas repostas de ambas as questões é uma situação confortável nesse quesito, tendo em vista que mais de $50 \%$ dos municípios declararam que se articulam bem com a União e o Estado, e quase $90 \%$ dos municípios declararam já incorporar ou iniciam essa incorporação, ações de proteção e defesa civil em seu planejamento. Isso significa que a maioria dos municípios do Estado de São Paulo possui instrumentos para lidar bem com os desafios desta política pública, tendo em vista que, na sua maioria, os municípios lidam bem com os interesses conflitantes envolvidos nessa problemática, quais sejam: questões sociais, econômicas e políticas. Todavia, é conveniente destacar a necessidade do efetivo conhecimento dos problemas e das possíveis soluções por parte dos agentes públicos, para que não tenham dificuldades em planejar tais soluções.

Também há relação entre as questões 3 e 4, pois ambas tratam de áreas de risco. A questão 3 aborda a identificação e o mapeamento das áreas de risco de desastre e a 4 aborda a fiscalização das áreas de risco e a vedação a novas ocupações nessas áreas. Com relação ao mapeamento, $80 \%$ dos municípios declararam já ter suas áreas de risco mapeadas, o que já era esperado, pois muitos dos municípios selecionados foram priorizados para mapeamento em face de recorrência de eventos de ordem meteorológica, hidrológica e geológica, através de parcerias com entidades especializadas como o Instituto de Pesquisas Tecnológicas (IPT) e o Instituto Geológico (IG). Já para a fiscalização e vedação de ocupações, apenas $41 \%$ dos municípios declararam estar em conformidade com essa exigência, ou seja, mais da metade dos municípios ainda não está preparada nesse quesito. Esse fato é preocupante, tendo em vista que combater a ocupação em áreas vulneráveis e promover a realocação da população residente nessas áreas é condição imprescindível para minimizar a ocorrência/efeitos de desastres em uma comunidade. Devido ao caráter dinâmico do risco, os mapas de risco podem ficar obsoletos e é possível inferir que a fiscalização é uma maneira também de verificar a atualização desse mapeamento. Com a Lei nº 12.608/12, o 
Governo Federal passa a liberar verbas para aquisição de áreas e construção de novas habitações (BRASIL, 2012).

As questões 5, 8, 9 e 10 abordam a organização e administração de abrigos para assistência à população (questão 5); locais para o recebimento e triagem de doações (questão 8); métodos adequados de triagem das doações (questão 9); e critérios para compra de itens para operações de respostas a desastres (questão 10). No caso dos abrigos, $58 \%$ dos municípios declararam já terem constituído abrigos adequados. No caso dos locais para recebimento e triagem de doações, $65 \%$ declararam já estarem preparados para tanto, porém $42 \%$ declararam não possuir pessoal treinado em métodos adequados de triagem de material doado, assim como 42\% também declararam não possuir critérios claramente definidos para compra de itens necessários nas operações de respostas a desastres. Dentro desses tópicos, é importante ressaltar que não só a constituiçãao de locais protegidos e adequados para abrigar pessoas e insumos devem ser providenciados, mas ainda questões vinculadas a políticas de compra e gestão de estoques devem ser pensadas para um efetivo resultado na ajuda humanitária. Cabe também destacar que muitos municípios consideram a adaptação de escolas como abrigos e centros de triagem, o que não é recomendável (VALENCIO; SIENA; MARCHEZINI, 2011). Parcerias com fornecedores previamente selecionados e estoques preposicionados precisam ser pensados. Quanto ao local para doações e métodos de triagem, pesquisas ressaltam que a melhor prática é manter um ponto de apoio em que elas possam ser separadas antes de serem levadas ao local onde serão distribuídas e utilizadas (KAWASAKI et al., 2012; CARNEIRO et al., 2014). Alguns gabaritos para seleção e classificação de roupas e sapatos, que foram desenvolvidos por pesquisadores e disponibilizados à Cruz Vermelha, mostraram-se eficientes para uma rápida separação e distribuição desses itens.

A questão 6 trata de informação e emissão de alertas antecipados para a população, quando da iminência de um evento extremo. Nesse tópico, 30\% dos municípios declararam ainda não ter feito nada relacionado a protocolos de alerta e, apesar da maioria já estar preparada ou em fase final de preparação, o número é preocupante. Os alertas são de extrema importância, pois são capazes de minimizar prejuízos e perdas de vidas, no caso de uma ocorrência de desastre. Cada vez mais as 
tecnologias estão possibilitando a previsão antecipada do clima e as redes sociais já são usadas em diversos locais para a troca de informações entre os agentes da Defesa Civil e as comunidades em risco. Há ainda o Centro Nacional de Monitoramento e Alertas de Desastres Naturais (CEMADEN) que tem entre seus objetivos monitorar e emitir alertas, além de fornecer dados de sua rede observacional, em todo o território nacional, constituindo importante fonte de apoio aos diretamente envolvidos na gestão de riscos dos municípios.

A $7^{\mathrm{a}}$ questão aborda a necessidade de realizar regularmente exercícios simulados, conforme Plano de Contingência e Defesa Civil. Nesse ponto, uma grande parte dos municípios (70\%) declararam-se não totalmente aptos a realizar os simulados solicitados. Mesmo dentre aqueles que responderam positivamente à pergunta, foi detectado através de entrevistas que existe uma confusão entre simulados de desastres e simulados de resgate realizados, por exemplo, pelo Corpo de Bombeiros ou SAMU. No entanto, vale destacar que simulados são necessários para a instituição de uma cultura de prevenção, focada na redução dos riscos de desastres e, para tanto, é imprescindível o envolvimento da sociedade civil, pois trata-se também da capacitação das pessoas para uma correta reação em um evento de desastre, além de treinar os agentes de órgãos públicos e privados que atuam nessas ocorrências. Com os simulados será possível ainda ensinar às comunidades o significado de cooperação, solidariedade e desenvolver sua consciência social e de participação política.

Em relação ao preenchimento dos questionários, é relevante observar que não existia a necessidade de identificação pessoal ou do município, entretanto foi possível observar que muitos Coordenadores Municipais da Defesa Civil valorizaram demasiadamente as atividades realizadas ou a realizar. Outra observação foram algumas dificuldades de se acessar e navegar na internet e do preenchimento do questionário enviado através do SurveyMonkey ${ }^{\circledR}$. Um exemplo de dificuldade observada foi o preenchimento do questionário, que possuía duas páginas web e ocasionalmente a segunda página não se encontrava preenchida. Em alguns casos, os pesquisadores tiveram que, através de telefone, prestar esclarecimentos adicionais e auxiliar o coordenador no preenchimento. 


\section{Considerações finais}

Colocar em prática os dispositivos da Lei $n^{\circ}$ 12.608/2012 é um grande desafio. Será preciso encontrar caminhos que serão particulares a cada município, porém articulando ações conjuntas em âmbito nacional, estadual e municipal. Trata-se de um avanço, já que a lei faz uma junção entre as áreas de risco de desastres e as questões de planejamento e políticas de ordenamento territorial. Evoca o planejamento municipal com base em pesquisas e estudos, fazendo com que trabalhos tenham embasamento tecnológico e, ainda, incentivando a participação da sociedade civil. Estimula o desenvolvimento de cidades resilientes, com processos sustentáveis de urbanização, evitando a ocupação de áreas de risco, treinando as pessoas para que possam se proteger e minimizar a/as ocorrência/efeitos de desastres em uma comunidade. Incita a inclusão do tema prevenção a desastres nos currículos escolares e medidas para a qualificação permanente dos agentes de proteção e defesa civil.

A Defesa Civil do Estado de São Paulo participa da regulamentação da Lei $n^{\circ}$ 12.608/12, que ainda deve ser detalhada e explicitada para todos os estados e municípios brasileiros. Este trabalho retrata a situação atual do estado de São Paulo quanto aos principais dispositivos da lei, especialmente ao que se refere ao seu artigo $8^{\circ}$. Os resultados demonstraram que, apesar de, em muitos casos, os requisitos já estarem em atendimento, ainda há muito por ser feito para que os municípios atendam plenamente os seus dispositivos.

Algumas considerações e recomendações foram feitas para cada resultado obtido das questões elaboradas, mas vale complementar que a instituição de mecanismos integrados de gerenciamento de ações e a instituição de procedimentos comuns aos envolvidos nas ações de prevenção e resposta, podem gerar sinergia, aumentando a eficácia das ações, como destaca Manso SUTERIO; BELDERRAIN (2015). Além disso, é importante atentar para as questões da gestão do conhecimento, pois os agentes que atuam em campo muitas vezes são profissionais que não foram previamente treinados, mas que desenvolveram suas habilidades durante o atendimento a emergências; sendo assim, a construção de competências e a capacitação são mecanismos que precisam ser 
desenvolvidos e apoiados, para que as habilidades desses agentes sejam elevadas a níveis mais profissionais, apoiadas por treinamento e compartilhamento das informações (UCHOA; MONTEIRO, 2012).

Assim, espera-se que este estudo contribua com a Defesa Civil de São Paulo, na medida em que fornece uma visão geral da situação atual dos seus municípios, frente aos requisitos da lei, e que também as sugestões sirvam como guia para as próximas ações e decisões, favorecendo uma melhoria em seu desempenho para a construção da resiliência em todos os seus municípios.

\section{Agradecimentos}

Os autores agradecem aos Coordenadores Municipais de Defesa Civil do Estado de São Paulo pelas informações e contribuições à pesquisa, em especial ao Capitão M. Kamada da Defesa Civil Estadual, pela presteza e auxílio dados para que fosse possível a execução deste artigo. Agradecem também ao CNPQ Conselho Nacional de Desenvolvimento Científico e Tecnológico (Processo: 456711/2014-7).

\section{Referências}

ALVES, Humberto Prates da Fonseca. ; OJIMA, Ricardo Vulnerabilidade às mudanças climáticas nas áreas urbanas do Estado de São Paulo: mudanças no regime de chuvas e características socioeconômicas e demográficas da população. In: ENCONTRO NACIONAL DA ANPPAS, IV, Brasília, I, 04 a 06/06/2008, Anais... Brasília: ANPPAS, 2008.

AMORIM, Marisa Fasura de; QUELHAS, Osvaldo Luiz Gonçalves; MOTTA, Ana Lúcia Torres Seroa da. Resiliência das Cidades Frente a Chuvas Torrenciais: Estudo de Caso do Plano de Contingência da Cidade Do Rio De Janeiro. Revista Sociedade \& Natureza, v.26, n.3, p.519534, 2014

BELTRÃO, Taciana. Com nova lei, defesa civil ainda se estrutura para salvar vidas. Jornal do Senado, Brasília, ano 20, n. 4.087, 20/05/2014. Disponível em: <http://www12.senado.gov.br/jornal/edicoes/2014/05/20>. Acesso em: 15/05/2015.

BRASIL Lei ${ }^{\circ} 12.608$ de 10 de abril de 2012. Institui a Política Nacional de Proteção e Defesa Civil - PNPDEC; dispõe sobre o Sistema Nacional de Proteção e Defesa Civil - 
SINPDEC e o Conselho Nacional de Proteção e Defesa Civil - CONPDEC; autoriza a criação de sistema de informações e monitoramento de desastres; altera as Leis nos 12.340, de 10 de dezembro de 2010, 10.257, de 10 de julho de 2001, 6.766, de 19 de dezembro de 1979, 8.239, de 4 de outubro de 1991, e 9.394, de 20 de dezembro de 1996; e dá outras providências. Diário Oficial da União, Brasília, DF: Poder Executivo,2012.

BRAUCH, Hans G. Threats, challenges, vulnerabilities and risks in environmental and human security. UNU-EHS, 2005.

CAPACITAÇÃO básica em defesa civil. 5. ed. Florianópilis: CEDEP/UFSC, 2014. textos: Janaína. Marcos de Oliveira; Maria Cristina Dantas; Pedro Paulo Souza; Regina Panceri]. Disponível em: http://www.ceped.ufsc.br/wpontent/uploads/2013/01/Livro_DefesaCivil_5ed-Diagramado-Completo-online.pdf. Acesso em: 27/03/2016.

CARNEIRO, Priscilla Vieira, COSTA, Otávio Augusto Fernandes BRITO JUNIOR, Irineu; YOSHIZAKI, Hugo Tsugunobu Yoshida Uma análise sobre o pós-desastre das chuvas em Cubatão ocorridas em fevereiro de 2013. In: XXVIII Congresso Nacional de Pesquisa e Ensino em Transporte - ANPET, , Curitiba 24 a 28 de novembro de 2014, Anais... Curitiba: Anpet, 2014.

EM-DAT. The OFDA/CRED International Disaster Database. Brussels: Université Catholique de Louvain, 2014.

FREITAS, Carlos Machado de; CARVALHO, Mauren Lopes de; XIMENES, Elisa Francioli; ARRAES, Eduardo Fonseca; GOMES, José Orlando. Vulnerabilidade socioambiental, redução de riscos de desastres e construção da resiliência: lições do terremoto no Haiti e das chuvas fortes na Região Serrana, Brasil. Ciênc. Saúde coletiva. [online], vol.17, n.6, pp.1577-1586. Disponível em:... Acesso em:

KAWASAKI, Bruno César, BRITO JUNIOR, Irineu; LEIRAS, Adriana; YOSHIZAKI, Hugo Tsugunobu Yoshida Logística de resposta a desastres: o caso das chuvas no Vale do Paraíba Paulista em Janeiro de 2010 [artigo online]. In: ENCONTRO NACIONAL DE ENGENHARIA DE PRODUÇÃO ENEGEP, XXXI, Bento Gonçalves, de 15 a 18 de out. de 2012. Disponível em:

http://www.abepro.org.br/biblioteca/ENEGEP2012_TN_WIC_157_915_20003.pdf. Acesso em.16/03/2016.

MANSO, Daniel Ferreira.; SUTERIO, Ricardo.; BELDERRAIN, Mischel Carmen Neyra Estruturação do problema de gerenciamento de desastres do estado de São Paulo por intermédio do método Strategic Options Development and Analysis. Gest. Prod., São Carlos, v. 22, n. 1, p. 4-16, 2015. 
MATTEDI, Marcos Antônio.; FRANK, Beate; SEVEGNANI, Lucia; BOHN, Noemia O desastre se tornou rotina. In: FRANK, Beate; SEVEGNANI, Lucia. (Org.). Desastre de 2008 no Vale do Itajaí: água, gente e política. Blumenau: Agência de Água do Vale do Itajaí, 2009.

MOURA, Rosa; SILVA, Luis Antonio de Andrade. Desastres Naturais ou negligência humana. Revista Eletrônica Geografar, Curitiba V.III, n.I, p. 58-72. 2008. Disponível em: <http://revistas.ufpr.br/geografar/article/view/12910>. Acesso em: 12/11/2015

O'RIORDAN, Timothy Precautionary Principle. In: Tolba, M.K. (Ed.). Encyclodia of Global Environmental Change. Chichester, UK: John Wiley, 2002.

ONU. World Urbanization Prospects, the 2014 revision. 2014. Disponível em: <http://esa.un.org/unpd/wup/CD-ROM/>. Acesso em 08/02/2016.

SANTOS, Álvaro Rodrigues dos Áreas de risco: A Lei n 12.608e os limites dos alertas pluviométricos. Revista Engenharia, $n^{\circ}$ 610. 2012. Disponível em: <http://www.brasilengenharia.com/portal/images/stories/revistas/edicao610/610_palavra 03.pdf>. Acesso em: 03/05/2015.

SANTOS, Roseli Ferreira dos Vulnerabilidade Ambiental: desastres naturais ou fenômenos induzidos? . Brasília: Ministério do Meio Ambiente - MMA, 2007.

SARNEY FILHO, José Palestra o sobre desastres ambientais. 2012. Disponível em: <http://www.sarneyfilho.com.br/site/index.php/noticias/item/45789-palestra-dodeputado-sarney-filho-sobre-desastres ambientais?tmpl=component\&print=1>. Acesso 03/05/2015.

SIEBERT, Cláudia Resiliência urbana: planejando as cidades para conviver com fenômenos climáticos extremos. In: Encontro da Associação Nacional de Pós-Graduação e Pesquisa em Ambiente e Sociedade ENAPPAS, VI, Belém 18 a 21/09/2012. Anais.... Belém: UFPA, 2012.

SILVA, Evander de Oliveira Cidades resilientes: novos rumos para uma cidade do futuro. 2015. Disponível em: http://evanderoliveira.jusbrasil.com.br/artigos/152036518/cidadesresilientes-novos-rumos-para-uma-cidade-do-futuro. Acesso em 15/12/2015.

THE WORLD BANK; UNITED NATIONS (UN) Natural hazards, unnatural disasters: the economics of effective prevention. Washington DC:WB/UN. 2010.

TRIOLA, Mario F. Introdução à estatística: atualização da tecnologia. $11^{a}$ ed. Rio de Janeiro: LTC, 2014. 
UCHOA, Mariana.; MONTEIRO, Vera Lúcia. Gestão do conhecimento em ações humanitárias: mais um Desafio da Área. Fasci-Tech - Periódico Eletrônico da FATEC. São Caetano do Sul, v.1, n. 6, p. 90-100. 2012. . Disponível em www.fatecsaocaetano.edu.br/fascitech/index.php/fascitech/article/download/65/64>. Acesso em: 12/11/2015.

UNISDR . Como Construir Cidades Mais Resilientes: um guia para gestores públicos locais. Genebra, Suíça, 2012. Tradução de: How to Make Cities More Resilient - A Handbook for Mayors and Local Government Leaders.

UNISDR. Construindo Cidades Resilientes: minha cidade está se preparando. Tradução Sarah Marcela Chinchilla Cartagena . Brasília: Ministério Da Integração Nacional: UFSC/Centro Universitário de Estudos e Pesquisas Sobre Desastres, 2009. Campanha Mundial de Redução de desastres. . Disponível em: <http://eird.org/cursobrasil/docs/modulo7/4.SEDEC-Cidades-Resilientes.pdf>. Acesso em 08/02/2016.

UNISDR. Sendai Framework for Disaster Risk Reduction 2015-2030. UN world conference on disaster risk reduction, 2015. March 14-18, Sendai, Japan. Geneva: United Nations Office for Disaster Risk Reduction; 2015. Disponível em: <http://www.wcdrr.org/uploads/ Sendai_Framework_for_Disaster_Risk_Reduction_2015-2030.pdf $>$. Acesso em: $08 / 02 / 2016$.

VALENCIO, Norma Felicidade Lopes da Silva, SIENA, Mariana; MARCHEZINI, Victor Abandonados nos desastres: uma análise sociológica de dimensões objetivas e simbólicas de afetação de grupos sociais desabrigados e desalojados. Conselho Federal de Psicologia, Brasília DF, 2011. 